Whitley, R. \& Hickling, F. W. (2007) Open papers, open minds? Media representations of psychiatric de-institutionalisation in Jamaica. Transcultural Psychiatry, 44, 659-671.
World Health Organization (2005) Jamaica. In Project Atlas: Resources for Mental Health, pp. 254-256. WHO. Available at http://www.who. int/mental_health/evidence/atlas/ (accessed October 2009).

\title{
A decade of mental health services in Timor-Leste
}

\section{Zoe Hawkins BM BCh MA}

Advisor to the Ministry of Health for Mental Health, Epilepsy and Health Research, Democratic Republic of Timor-Leste email zoe.hawkins@doctors.org.uk

\begin{abstract}
The Democratic Republic of Timor-Leste (East Timor) occupies the eastern half of the island of Timor, which lies north-west of Australia and within the eastern Indonesia archipelago. The population is approximately one million, of whom $45 \%$ are below the age of 15 . Average life expectancy is 59.5 years and $50 \%$ of the population live below the national poverty line of US $\$ 0.88$ per day. The official languages are Tetun and Portuguese, with Indonesian also used. The majority of the population are Catholic but also hold traditional animist beliefs.

Timor-Leste, a Portuguese colony for over 400 years, was invaded by Indonesia in 1975 following Portugal's rapid decolonisation. During the following 24 years of occupation, anti-insurgent and terror campaigns were carried out by the Indonesian military, with mass internal displacements of people and war-induced famines. Following a majority vote for independence in a 1999 referendum, a violent backlash from pro-Indonesia groups caused further deaths and mass destruction of buildings and infrastructure. Intervention by Australian-led peacekeeping forces restored stability, and the territory was administered by a United Nations mission until full independence was gained in 2002.
\end{abstract}

\section{History of mental health services}

During the years of Indonesian administration there were no mental health services in East Timor. In 1999, Psychosocial Recovery and Development in East Timor (PRADET) was founded by a partnership of mental health practitioners from Australia. Sixteen Timorese health workers underwent basic mental health training in Australia and returned to form the core staff of PRADET (Zwi \& Silove, 2002). In addition to providing assessment, diagnosis and treatment for people with mental illness, the staff of PRADET trained district health nurses in their follow-up care.

In 2002, the government established the East Timor National Mental Health Project (ETNMHP) as its mental health service, with technical support and training provided by a team of Australian mental health workers. PRADET continued as a local non-governmental organisation (NGO) to complement government services by providing psychosocial support, counselling and community education. In 2008, the ETNMHP became the Department of Mental Health within the Ministry of Health.

\section{Psychiatric morbidity}

An epidemiological study conducted in 2004 reported a point prevalence of psychosis (meeting DSM-IV criteria) of $1.35 \%$ and post-traumatic stress disorder of $1.47 \%$ (Silove et al, 2008). Since January 2008, the mental health service has seen a total of 3881 clients, of whom 1026 (26\%) have had a primary diagnosis of epilepsy. There are no data on the prevalence of different mental disorders within the remaining case-load. However, mental health workers report that psychotic disorders form the majority of cases, followed by depressive disorder.

\section{Mental health policy and legislation}

The government has a national mental health strategy (Ministry of Health Timor-Leste, 2005), which emphasises both a primary care approach to mental health services and partnerships with non-government service providers. There is currently no mental health legislation.

\section{Infrastructure}

The 260-bed National Hospital (Hospital Nacional Guido Valadares) is located in Dili, the capital, and provides secondary and tertiary healthcare services. There are also five regional referral hospitals in the districts. The National Hospital acts as the national referral centre and is the principal clinical training centre for health personnel studying in Timor-Leste. At present there is no mental health bed allocation and no psychiatric hospital.

Each of the 13 districts in Timor-Leste has a district health office, where clinical services for the area are coordinated and supervised. 
Sixty-five community health centres (CHCs) - approximately one per subdistrict - provide primary healthcare services, including out-patient clinics, simple laboratory testing, health promotion and preventive health services such as immunisations. Eight CHCs have in-patient facilities.

There are 193 health posts located across Timor-Leste, which are smaller health centres staffed by midwives and nurses. Basic drugs are available but there are no laboratory or in-patient services. In addition, a programme called Integrated Community Health Services (Servisu Integradu da Saúde Communitária, SISCa) provides monthly communitybased health services within each village, including health promotion, and interventions in areas such as nutrition, maternal and child health, infectious disease prevention and environmental health.

\section{Mental health services}

All basic health services, including mental health and medication, are provided free of charge to Timorese people. Two internationally recruited psychiatrists (from Cuba and Papua New Guinea) work in Timor-Leste. Both are based in Dili, although one makes brief visits to the districts. Essentially, there are 1.14 psychiatrists per 100000 population in Dili, and 0 in the rest of the country.

Each district has an allocated mental health worker with basic training in mental health and a background in nursing or public health. In addition, $25 \%$ of $\mathrm{CHCs}$ have a general nurse who has also received basic training in mental health. These nurses form the primary service for people presenting with mental illness, with more difficult cases referred to the mental health worker for case management. Referrals for initial assessment can also be made directly to counsellors working in PRADET. District case-loads range between 100 and 200 clients, with referrals coming from the police, families, the church and village chiefs. There are no social workers or psychologists working in the government or NGO services.

\section{Pharmaceutical interventions}

Psychotropic medication is ordered by the district health office from the central medical stores in Dili (Serviço Autónomo de Medicamentos e Equipamentos de Saúde, SAMES), based upon calculations of monthly use from each $\mathrm{CHC}$. The medication is delivered by truck to each district every 3 months and distributed to CHCs. Clients or family members must then collect the prescription from the $\mathrm{CHC}$ themselves. Basic psychotherapeutic drugs are available and can be prescribed by the two psychiatrists, the district mental health workers and more senior general nurses.

\section{Health workforce training}

\section{Pre-service training}

The Ministry of Health, through the Institute of Health Sciences (Instituto de Ciências da Saúde, ICS), provides pre-service training to health workers in the country. This includes upgrading nurses and midwives to diploma 3 level, and providing courses in laboratory technology, pharmacy technology, anaesthetics nursing, eye-care nursing and radiography at diploma 1 level.

Currently, two out of every three doctors in the country (162 out of 243) are from Cuba. This is a result of a joint initiative between the governments of Cuba and TimorLeste known as the Cuban Medical Brigade, which provides primary care physicians and other health staff from Cuba to fill vacant posts within Timor-Leste.

The Ministry of Health collaborates with the Cuban Medical Brigade and the National University of Timor-Lorosae (Universidade Nacional Timor-Lorosae, UNTL) in providing pre-service courses in medicine (currently 150 students), nursing (50 students per year) and midwifery (50 students per year). Two private universities provide undergraduate training in public health.

In addition, through assistance from the Cuban government, a pre-service medical training programme for nearly 700 Timorese students is provided in Cuba. Psychiatry is taught in a 10-week block during the fifth year. A small number of Timorese students have donor-funded scholarships to attend medical schools in other countries.

\section{Postgraduate training}

There is no formal postgraduate training of health personnel in Timor-Leste. However, there are more than 100 scholarship holders pursuing postgraduate training courses in Indonesia, Fiji, Malaysia and Papua New Guinea. There is currently one Timorese doctor completing postgraduate training in psychiatry in Papua New Guinea.

\section{Traditional healers and religious beliefs}

There are strong animist beliefs in Timorese culture. People with mental illness (bulak) and their families may feel they are being punished by an ancestral spirit for causing offence, perhaps by walking across a sacred area or swimming in a sacred river. The spirit takes the form of a tree or stone in the village. People who suffer from epilepsy (bibi maten, literally 'dying goat') are sometimes thought to have an angry ancestor spirit within them. Traditional healers use herbal treatments, which may include berries from the 'spirit' tree. An animal might be sacrificed and its blood poured over the stone or tree. The healers use trances, smoke, chanting and beating the person with a mental illness to remove the angry spirit. These actions are used in parallel with Catholic practices, with the family praying for forgiveness at the graveyards of the ancestors, and attending church to pray for healing.

\section{The way ahead}

Conflict, violence, large-scale human rights abuses and civil unrest are all elements of Timor-Leste's recent history, and have been shown to be associated with poor mental health (Mollica et al, 2005). In the context of this history, and as a young, low-income country, Timor-Leste is addressing significant challenges in the areas of infrastructure, human resources, financial constraints (short- and long-term prioritisation of resources) and poverty. 
The mental health system can begin to address these challenges by improving access to mental healthcare, strengthening and expanding the mental health workforce, and prioritising long-term funding for mental health.

Mental health education and promotion activities must be maintained and further developed to reduce stigma and discrimination. The implementation of appropriate and comprehensive mental health legislation is necessary to protect the human rights and dignity of Timorese people with mental disorders.

\section{References}

Ministry of Health Timor-Leste (2005) National Mental Health Strategy for a Mentally Healthy Timor-Leste. Ministry of Health, Democratic Republic of Timor-Leste.

Mollica, R. F., Cardozo, B., Osofsky, H., et al (2005) Mental health in complex emergencies. Lancet, 364, 2058-2067.

Silove, D., Bateman, C. R., Brooks, R. T., et al (2008) Estimating clinically relevant mental disorders in a rural and an urban setting in postconflict Timor Leste. Archives of General Psychiatry, 65, 1205-1212.

Zwi, A. \& Silove, D. (2002) Hearing the voices: mental health services in East Timor. Lancet, 360, s45-s46.

\section{Mental healthcare in Serbia}

\section{Dusica Lecic Tosevski, ${ }^{1}$ Saveta Draganic Gajic ${ }^{2}$ and Milica Pejovic Milovancevic ${ }^{2}$}

'Professor of Psychiatry, School of Medicine, University of Belgrade, Serbia, email dusica.lecictosevski@eunet.rs ${ }^{2}$ School of Medicine, University of Belgrade, Institute of Mental Health, Belgrade, Serbia

Sisis erbia is located on the Balkan peninsula, which served for centuries as a vulnerable crossroads between the East and the West. At the beginning of the 1990s, some of the republics of the former Yugoslavia, including Serbia, were involved in disastrous civil conflicts. In 2006 Serbia became a sovereign republic. At the 2002 census, its population was 7498000 .

The country has been exposed to many severe stressors, such as civil war in neighbouring countries, United Nations economic sanctions, which lasted for 3.5 years, and 11 weeks of NATO bombing in 1999. As a consequence, Serbia has experienced the destruction of infrastructure, large numbers of refugees and internally displaced people (currently there are half a million of them in Serbia), social instability, economic difficulties and deterioration of its healthcare system. In addition, a serious problem is the brain drain, since around 300000 people, mostly young intellectuals, have left the country in recent years (Lecic Tosevski \& Draganic Gajic, 2005).

After 2000, the country underwent economic liberalisation, and experienced relatively fast economic growth: gross domestic product per capita rose from US\$1.160 in 2000 to US\$6.782 in 2008, according to the International Monetary Fund (2008). The country is now passing through social transition and harmonisation with the European Union (EU). At present, the main problems are the high unemployment rate $(18.8 \%$ in 2008 and currently rising due to the economic crisis) and the large trade deficit (US\$11 billion). The major source of finance for public health is the national Health Insurance Fund, to which is allocated $6.1 \%$ of gross domestic product.

\section{Mental disorders}

The events outlined above caused a steady rise in mental and behavioural disorders. The prevalence of mental disorders increased by $13.5 \%$ between 1999 and 2002 and they now represent the second largest public health problem, after cardiovascular disease. The incidence rates of stress-related disorders, depression, psychosomatic illnesses, substance misuse and suicide are still high, as are rates of delinquency and violence among young people (Lecic Tosevski et al, 2007). Furthermore, the burnout syndrome is pronounced in many physicians, who have shared adversities with their patients and experienced secondary traumatisation (Lecic Tosevski et al, 2006). An international multicentre study carried out 7 years after major trauma has shown that the prevalence of chronic post-traumatic stress disorder (PTSD) is still very high (current, 18.8\%; lifetime, 32.3\%), as is that of major depressive episode (current, 26.2\%; recurrent, 14.4\%) (Priebe et al, 2009).

\section{Mental health policy and legislation}

In 2000, when the international community decided to take a proactive attitude rather than intervening only during crises, nine countries entered the Stability Pact for SouthEastern Europe (SEE): Albania, Bosnia and Herzegovina, Bulgaria, Croatia, the Former Yugoslav Republic of Macedonia, Moldova, Montenegro, Romania and Serbia. The mental health project 'Enhancing social cohesion through strengthening community mental health services' (Mental Health Project for SEE, http://www.seemhp.ba/index.php) brought together experts from the region with the aim of harmonising national mental health policies and legislation. The renewal of collaboration was also important for conflict resolution and reconciliation.

The National Committee for Mental Health was established in January 2003 by the Serbian Ministry of Health. As a coordinating body of the SEE Mental Health Project, the Committee prepared a national policy and action plan, and drafted a law on the protection of rights of persons 